\title{
Somatostatin versus octreotide in the treatment of patients with gastrointestinal and pancreatic fistulas
}

\author{
Emanuel Leandros MD PhD ${ }^{1}$, Pantelis T Antonakis MD ${ }^{1}$, Konstantinos Albanopoulos MD ${ }^{1}$, \\ Chris Dervenis MD², Manousos M Konstadoulakis MD PhD ${ }^{1}$
}

E Leandros, PT Antonakis, K Albanopoulos, C Dervenis, MM Konstadoulakis. Somatostatin versus octreotide in the treatment of patients with gastrointestinal and pancreatic fistulas. Can J Gastroenterol 2004;18(5):303-306.

BACKGROUND AND PURPOSE: Gastrointestinal and pancreatic fistulas are characterized as serious complications following abdominal surgery, with a reported incidence of up to $27 \%$ and $46 \%$, respectively. Fistula formation results in prolonged hospitalization, increased morbidity/mortality and increased treatment costs. Conservative and surgical approaches are both employed in the management of these fistulas. The purpose of the present study was to assess, evaluate and compare the potential clinical benefit and cost effectiveness of pharmacotherapy (somatostatin versus its analogue octreotide) versus conventional therapy.

PATIENTS AND METHODS: Fifty-one patients with gastrointestinal or pancreatic fistulas were randomized to three treatment groups: 19 patients received $6000 \mathrm{IU} /$ day of somatostatin intravenously, 17 received $100 \mu \mathrm{g}$ of octreotide three times daily subcutaneously and 15 patients received only standard medical treatment.

RESULTS: The fistula closure rate was $84 \%$ in the somatostatin group, $65 \%$ in the octreotide group and $27 \%$ in the control group. These differences were of statistical significance $(\mathrm{P}=0.007)$. Overall mortality rate was less than $5 \%$ and statistically significant differences in mortality among the three groups could not be established. Overall, treatment with somatostatin and octreotide was more cost effective than conventional therapy (control group), and somatostatin was more cost effective than octreotide. The average hospital stay was 21.6 days, 27.0 and 31.5 days for the somatostatin, octreotide and control groups, respectively.

CONCLUSIONS: Data suggest that pharmacotherapy reduces the costs involved in fistula management (by reducing hospitalization) and also offers increased spontaneous closure rate. Further prospective studies focusing on the above parameters are needed to demonstrate the clinicoeconomic benefits.

Key Words: Closure rate; Gastrointestinal fistulas; Pancreatic fistulas
La somatostatine par rapport à l'octréotide dans le traitement des patients atteints de fistules gastro-intestinales ou pancréatiques

HISTORIQUE ET OBJECTIF : Les fistules gastro-intestinales et pancréatiques sont caractérisées par des complications graves suivant une opération abdominale, l'incidence déclarée pouvant atteindre $27 \%$ et 46 \%, respectivement. La formation de fistules entraîne une hospitalisation prolongée ainsi qu'une augmentation de la morbidité, de la mortalité et du coût des traitements. Des démarches tant traditionnelles que chirurgicales sont utilisées dans la prise en charge de ces fistules. La présente étude visait à évaluer et à comparer le bénéfice clinique potentiel et la rentabilité de la pharmacothérapie (somatostatine par rapport à son analogue, l'octréotide) par rapport au traitement traditionnel.

PATIENTS ET MÉTHODOLOGIE : Cinquante et un patients présentant des fistules gastro-intestinales ou pancréatiques ont été répartis de manière aléatoire entre trois groupes de traitement : 19 patients ont reçu $6000 \mathrm{UI} /$ jour de somatostatine intraveineuse, 17 ont reçu $100 \mu \mathrm{g}$ d'octréotide sous-cutané trois fois par jour, et 15 patients n'ont reçu que le traitement médical habituel.

RÉSULTATS : Le taux de fermeture des fistules était de $84 \%$ dans le groupe prenant de la somatostatine, de $65 \%$ dans celui prenant de l'octréotide et de $27 \%$ dans le groupe témoin. Ces différences étaient statistiquement significatives $(\mathrm{P}=0,007)$. Le taux de mortalité global était inférieur à $5 \%$, et on n'a pas pu établir de différence statistiquement significative de la mortalité entre les trois groupes. Dans l'ensemble, le traitement à la somatostatine ou à l'octréotide était plus rentable que le traitement traditionnel (groupe témoin), et la somatostatine l'était plus que l'octréotide. L'hospitalisation moyenne était de 21,6 jours, de 27,0 jours et de 31,5 jours pour la somatostatine, l'octréotide et le groupe témoin, respectivement.

CONCLUSIONS : D'après les données, la pharmacothérapie réduit les coûts de prise en charge des fistules (en diminuant la durée d'hospitalisation) et procure également un accroissement du taux de fermeture spontanée. Des études prospectives supplémentaires portant sur les paramètres précédents s'imposent pour en démontrer les bénéfices clinicoéconomiques.
G xternal fistula formation is a serious complication of gasEtrointestinal and pancreatic surgery. Mortality ranges between $5 \%$ and $30 \%$ in the case of enterocutaneous fistulas and $5 \%$ and $10 \%$ in the case of pancreatic fistulas (1-3). In most patients, spontaneous fistula closure occurs when essential treatment principles are followed, such as elimination of sepsis, adequate drainage, proper nutritional support, correction of fluid and electrolyte disturbances and skin care. Still, morbidity, mortality, increased length of hospitalization, cost and the psychological consequences to the patient render the conservative medical treatment insufficient $(1,4)$.

${ }^{1}$ First Department of Propaedeutic Surgery, Hippocration Hospital, Athens Medical School; ${ }^{2}$ First Department of Surgery, Konstantopoulion, Agia Olga Hospital, Athens, Greece

Correspondence and reprints: Dr Manousos M Konstadoulakis, Kalvou 24, 15452, Old Psichico, Athens, Greece. Telephone +306972241980,

fax+302106722259, e-mail labsures@med.uoa.gr

Received for publication December 2, 2003. Accepted March 4, 2004 
TABLE 1

Demographic and clinical characteristics of 51 patients with enterocutaneous or pancreaticocutaneous fistulas, treated with somatostatin, octreotide or standard medical treatment (SMT) only

\begin{tabular}{|c|c|c|c|c|}
\hline & Somatostatin group & Octreotide group & SMT group & Total \\
\hline Patients, n (\%) & $19(37.3)$ & $17(33.3)$ & $15(29.3)$ & $51(100)$ \\
\hline Age in years, median (SD) & $61.5(16.9)$ & $70.0(11.1)$ & $72.0(13.0)$ & $67.0(14.7)$ \\
\hline \multicolumn{5}{|c|}{ Kruskal Wallis test $=6.0, D F=2, P=0.049$} \\
\hline \multicolumn{5}{|l|}{ Sex, n (\%) } \\
\hline Male & $12(38.7)$ & $9(29.0)$ & $10(32.3)$ & $31(60.8)$ \\
\hline Female & $7(35.0)$ & $8(40.0)$ & $5(25.0)$ & $20(39.6)$ \\
\hline \multicolumn{5}{|l|}{$\chi^{2}=0.671, P=0.715$} \\
\hline \multicolumn{5}{|l|}{ Diagnostic methods, n (\%) } \\
\hline Computed tomography & $3(50.0)$ & $2(33.3)$ & $1(16.7)$ & $6(12.5)$ \\
\hline Fistulography & $11(30.6)$ & $13(34.5)$ & $12(36.1)$ & $36(75.0)$ \\
\hline Other & $5(55.5)$ & $2(22.2)$ & $2(22.2)$ & $9(17.6)$ \\
\hline \multicolumn{5}{|l|}{ Fistula type, n (\%) } \\
\hline Enteric & $12(31.6)$ & $12(31.6)$ & $14(36.8)$ & $38(74.5)$ \\
\hline Pancreatic & $7(53.8)$ & $5(38.4)$ & $1(7.7)$ & $13(25.5)$ \\
\hline \multicolumn{5}{|l|}{$\chi^{2}=2.752, D F=2, P=0.253$} \\
\hline \multicolumn{5}{|l|}{ Enteric fistula origin, $\mathrm{n}(\%)$} \\
\hline Stomach & $1(25.0)$ & $2(50.0)$ & $1(25.0)$ & $4(8.3)$ \\
\hline Small and large intestine & $7(30.4)$ & $4(17.4)$ & $12(52.2)$ & $23(60.5)$ \\
\hline Bile duct & $3(37.5)$ & $4(50)$ & $1(12.5)$ & $8(21.1)$ \\
\hline Other & $1(33.3)$ & $2(66.7)$ & - & $3(7.8)$ \\
\hline \multicolumn{5}{|l|}{ Output category, n (\%) } \\
\hline Low & $9(33.3)$ & $8(29.6)$ & $10(37.0)$ & $27(56.3)$ \\
\hline High & $10(41.7)$ & $9(37.5)$ & $5(20.8)$ & $24(47.1)$ \\
\hline$\chi^{2}=1.245, D F=2, P=0.537$ & & & & \\
\hline
\end{tabular}

DF Degrees of freedom

Somatostatin and its synthetic analogue, octreotide, are known to reduce gastrointestinal, biliary and pancreatic secretions (5-7). These properties render them good candidates for the treatment of gastrointestinal and pancreatic fistulas. Their effectiveness has been examined in several clinical trials, the results being rather inconclusive $(7-14)$. The present study was conducted to evaluate and compare the potential benefits of the administration of these two agents to patients with gastrointestinal or pancreatic fistulas.

\section{METHODS AND MATERIALS}

In this prospective randomized controlled study 51 consecutive patients with gastrointestinal (38 patients, $74.5 \%$ ) or pancreatic fistulas (13 patients, 25.5\%) were included. All patients were treated in our surgical clinic between December 1995 and April 1999 and received standard medical treatment (SMT) plus somatostatin (16 patients), octreotide (17 patients), or SMT (control group, 15 patients). Somatostatin was given by continuous intravenous infusion at a dose of $6000 \mathrm{IU} /$ day, while octreotide was given at a dose of $100 \mu \mathrm{g}$ three times daily, subcutaneously. A local ethics committee approved the design of this study.

Demographic and clinical characteristics were recorded for all patients (Table 1). The diagnosis of fistula origin was attained, when necessary, by computed tomography scan or fistulography (Table 1). The fistulas were classified according to type (pancreatic or enteric). Enterocutaneous fistulas were further subdivided by origin (Table 1). Fistulas were also classified as high or low output on presentation (Table 1). Enterocutaneous fistulas were classified as high output fistulas when the daily output on presentation exceeded $500 \mathrm{~mL}$, while pancreaticocutaneous fistulas were considered as high output fistulas when the daily output exceeded $200 \mathrm{~mL}(12,15)$.

The results were evaluated based on the following parameters: length of in-hospital stay; days until restoration of regular oral nutrition; presence or absence of complications; fistula outcome on discharge (spontaneous closure or surgical/other treatment); days until fistula closure; and outcome on discharge. Length of in-hospital stay, time until restoration of nutrition by mouth and time to fistula closure were recorded from the day of fistula onset for patients with a fistula of recent onset (41 patients, $80.4 \%$ ) and from the day of admission for patients with a fistula of nonrecent onset (more than eight days before admission, 10 patients, $19.6 \%)$. The total cost for treatment was calculated based on data provided by the administrative department of our hospital. The figures provided included the total cost of the admission to the health insurance agency.

The statistical tests used were the $\chi^{2}$ test for categorical data and the Kruskal Wallis test for numerical data, and a $\mathrm{P}<0.05$ was considered statistically significant. All tests were double-sided.

\section{RESULTS}

The three groups of patients did not have the same demographic characteristics. Age varied significantly among the three groups (Kruskal Wallis test, $\mathrm{P}=0.049$, Table 1), with the patients in the SMT group being older (median age 72 years), followed by the patients in the octreotide group (median age 70 years) and in the somatostatin group (median age 61.5 years). However, because of the relatively small number of 
TABLE 2

The comparative evaluation of somatostatin, octreotide and standard medical treatment (SMT) groups, through several characteristics

\begin{tabular}{|c|c|c|c|c|}
\hline & Somatostatin group & Octreotide group & SMT group & Total \\
\hline Patients & $19(37.3 \%)$ & $17(33.3 \%)$ & $15(29.3 \%)$ & $51(100 \%)$ \\
\hline Days to oral nutrition, median (SD) & $13.0(5.7)$ & $13.0(12.1)$ & $17.0(11.5)$ & $13.0(10.2)$ \\
\hline Patients recieving oral nutrition & 19 patients & 17 patients & 14 patients & \\
\hline \multicolumn{5}{|l|}{ Kruskal Wallis test $=1.608, D F=2, P=0.448$} \\
\hline \multicolumn{5}{|l|}{ Outcome on discharge, $\mathrm{n}(\%)$} \\
\hline Dead & 0 & 0 & $2(100)$ & $2(3.9)$ \\
\hline Alive & $19(38.8)$ & $17(34.7)$ & $13(26.5)$ & $49(96.1)$ \\
\hline \multicolumn{5}{|l|}{$\chi^{2}=4.591, \mathrm{DF}=2, \mathrm{P}=0.101$} \\
\hline \multicolumn{5}{|l|}{ Complications, n (\%) } \\
\hline Yes & $8(32.0)$ & $7(28.0)$ & $10(40.0)$ & $25(49.0)$ \\
\hline No & $11(42.3)$ & $10(38.5)$ & $5(19.2)$ & $26(51.0)$ \\
\hline \multicolumn{5}{|l|}{$\chi^{2}=2.116, D F=2, P=0.347$} \\
\hline \multicolumn{5}{|l|}{ Outcome, n (\%) } \\
\hline Closure & $16(51.6 \%)$ & $11(35.5 \%)$ & $4(12.9 \%)$ & $31(60.1 \%)$ \\
\hline Other therapy & $3(15.0 \%)$ & $6(30.0 \%)$ & $11(55.0 \%)$ & $20(39.9 \%)$ \\
\hline \multicolumn{5}{|l|}{$\chi^{2}=11.6, \mathrm{DF}=2, \mathrm{P}=0.003$} \\
\hline Days to closure, median (SD) & $10.5(7.5)$ & $16.5(16.6)$ & $18.0(5.3)$ & $16.0(11.8)$ \\
\hline \multicolumn{5}{|l|}{ Kruskal Wallis test $=3.933, \mathrm{DF}=2, \mathrm{P}=0.140$} \\
\hline Days in hospital, median (SD) & $15(12.0)$ & $24(13.7)$ & $28(20.4)$ & $20.0(16.2)$ \\
\hline Kruskal Wallis test $=7.419, \mathrm{DF}=2, \mathrm{P}=0.024$ & & & & \\
\hline
\end{tabular}

DF Degrees of freedom

patients in each group, and because $\mathrm{P}=0.049$ is close to the border of 0.05 , this statistically significant result was not considered to reflect nonhomogeneity among the groups. The groups were well matched for sex $\left(\chi^{2}=0.671, \mathrm{P}=0.715\right)$ (Table 1).

The clinical characteristics of the three groups were similar. Patients with enterocutaneous fistulas outnumbered patients with pancreatic fistulas in all groups and no statistical differences could be established among the three groups $\left(\chi^{2}=2.8\right.$, $\mathrm{P}=0.253$ ) (Table 1). Low to high output ratio was approximately 1:1 in all groups and again, no statistically significant differences could be established $\left(\chi^{2}=1.245, \mathrm{P}=0.537\right)$ (Table 1).

Median length of in-hospital stay was 20 days (Table 2) and was 15,24 and 28 days for the somatostatin, octreotide and SMT groups, respectively. The difference was statistically significant (Kruskal Wallis test $=7.42, \mathrm{P}=0.024$ ) (Table 2). A difference between the two therapy arms was not established (Mann Whitney $\mathrm{U}$ test, $z=-1.745$, exact $\mathrm{P}=0.08$ ). The time interval until restoration of oral nutrition also did not vary significantly among the three groups (overall median 13.0 days, Kruskal Wallis test $=1.6, \mathrm{P}=0.448$ ) (Table 2). Similar results were obtained when the outcome on hospital discharge was evaluated. Overall death rate was 3.9\% (two of 51 patients). Both deaths occurred in the SMT group (not statistically significant). Overall complication rate in the series was $49.0 \%$ (25 of 51 patients). The complication rate in the SMT group was $66.7 \%$ (10 of 15 patients), and in the somatostatin and octreotide groups the complication rate was $42.1 \%$ (eight of 19 patients) and $41.2 \%$ (seven of 17 patients), respectively. Even though variation in the complication rate among the three groups was seen, these differences were not statistically significant $\left(\chi^{2}=2.116, \mathrm{P}=0.347\right)$. Overall closure rate was $60.1 \%$ ( 31 of 51 patients). Closure rate in the SMT group was $26.7 \%$ (four of 15 patients), while in the somatostatin group and in the octreotide group it was $84.2 \%$ (16 of 19 patients) and $64.7 \%$ (11 of 17 patients), respectively, with these differences being statistically significant (Kruskal Wallis test, $\mathrm{P}=0.003$ ). Conversely, the difference in closure rate between the somatostatin and the octreotide groups was not statistically significant (Fisher's exact test, $\mathrm{P}=0.255$ ). The median time for overall fistula closure was 16 days (Table 2). Median time to closure was 18 days for the SMT group, 10.5 days in the somatostatin group and 16.5 days in the octreotide group. These differences were not statistically significant (Kruskal Wallis test, $\mathrm{P}=0.140$ ).

The median cost of in-hospital stay was $€ 6,944$. A small variation was observed among the three groups and median cost was $€ 6,636, € 7,111$ and $€ 7,812$ for the somatostatin, octreotide and SMT groups, respectively. These differences were not statistically significant (Kruskal Wallis test, $\mathrm{P}=0.459$ ).

\section{DISCUSSION}

Gastrointestinal and pancreatic fistula formation is a major complication of abdominal surgery, and is associated with significant morbidity and mortality. The use of total parenteral nutrition was a major advancement in the field. It improved spontaneous fistula closure rates from $10 \%$ to $20 \%$ to $60 \%$ to $70 \%$, and reduced mortality from $16 \%$ to $62 \%$ to $10 \%$ to $20 \%$ $(2,16)$. Nevertheless, the prolonged in-hospital stay along with the improved but still significant mortality of fistulas rendered them a challenge in modern therapeutics. The reduction of gastrointestinal and pancreatic secretions has been a major goal in the pursuit of the optimal treatment, and somatostatin and octreotide have been used on this basis with variable results. In several centres, the administration of octreotide or somatostatin has been proposed as the treatment of choice in cases of gastrointestinal and pancreatic fistulas, because these drugs have been reported to reduce time of closure, despite the nonsignificant influence on mortality and complication rate 
$(9,12,17)$. In this clinical trial, 51 patients with gastrointestinal and pancreatic fistulas were recruited to evaluate and compare the potential clinical benefit from the administration of somatostatin and octreotide.

The overall death rate of less than $4 \%$ (two of 51 patients), the fistula closure rate of approximately $60 \%$ (31 of 51 patients) and the median time to fistula closure of 16 days observed in our study are within international standards (18). Even though we were unable to detect statistically significant differences in terms of mortality and complication rate, the differences in closure rate were statistically significant $(\mathrm{P}=0.003)$. In fact, spontaneous fistula closure rate was $27 \%$ in the SMT group, much less than in the somatostatin and the octreotide groups ( $84 \%$ and $65 \%$, respectively). This difference has not been reported in previous studies $(9,17,19)$. This could be attributed to the relatively low closure rate in the SMT group $(27 \%)$, which is strikingly low. Still, a similar closure rate in the SMT group has been reported in a multicentre, prospective, double-blind, placebo-controlled trial with octreotide, in which the spontaneous closure rates were $57 \%$ and $35 \%$ in the octreotide and SMT groups, respectively (8).

The differences in complication rate between the control group and the two groups receiving somatostatin and octreotide were noticeable, despite not being statistically significant. While in the control group the complication rate was $67 \%$, in the somatostatin and the octreotide groups it was $42 \%$ and $41 \%$, respectively. These results, along with the fact that no adverse effects were observed for either drug, are consistent

\section{REFERENCES}

1. McIntyre PB, Ritchie JK, Hawley PR, et al. Management of enterocutaneous fistulas: A review of 132 cases. Br J Surg 1984;71:293-6.

2. Rose D, Yarborough MF, Canizaro PC, Lowry SF. One hundred and fourteen fistulas of the gastrointestinal tract treated with total parenteral nutrition. Surg Gynecol Obstet 1986;163:345-50.

3. Martinez D, Zibari G, Aultman D, et al. The outcome of intestinal fistulae: The Louisiana State University Medical Center-Shreveport experience. Am Surg 1998;64:252-4.

4. Rubelowsky J, Machiedo GW. Reoperative versus conservative treatment for gastrointestinal fistulas. Surg Clin North Am 1991;71:147-50.

5. Ottery FD. Nutritional consequences of reoperative surgery in reccurent malignancy. Semin Oncol 1993;20:528-37.

6. Williams ST, Woltering EA, O'Dorizio TM, Fletcher WS. Effect of octreotide acetate on pancreatic exocrine function. Am J Surg 1989;157:459-62.

7. Woltering EA, O'Dorizio TM, Williams ST, et al. Treatment of nonendocrine gastrointestinal disorders with octreotide acetate. Metabolism 1990;39(9Suppl 2):176-9.

8. Sancho JJ, DiCostanzo J, Nubiola P, et al. Randomized double-blind placebo-controlled trial of early octreotide in patients with postoperative enterocutaneous fistula. Br J Surg 1995;82:638-41.

9. Torres AJ, Landa JI, Moreno-Azcoita M, et al. Somatostatin in the management of gastrointestinal fistulas. A multicenter trial. Arch Surg 1992;127:97-9.

10. Tsiotos GG, Smith CDE, Sarr MG. Incidence and management of pancreatic and enteric fistulas after surgical management of severe necrotizing pancreatitis. Arch Surg 1995;130:48-52. with the assumption that there is a clinical benefit from the administration of these two agents. Still, the number of patients included in this study is not sufficient to enable satisfactory statistical power and, thus, this clinical benefit could not be shown in terms of mortality and complication rate.

An important parameter in the treatment of fistulas is the cost effectiveness of the therapeutic modality. The significant cost of somatostatin and octreotide has always been a major drawback for their clinical use. We could not find differences in the cost of therapy based on economic data provided by the administrative authority of our hospital. It appears that the cost of therapy with somatostatin or octreotide may be similar to that of SMT, because there is higher closure rate during a shorter length of in-hospital stay.

That the comparison between somatostatin and octreotide yielded insignificant results for all the recorded parameters could also be attributed to the fact that only a small cohort was included. Still, somatostatin had better spontaneous closure rate $(84 \%$ versus $65 \%$ ) than octreotide and provided equivalent results in terms of complication rate (42\% versus $41 \%)$.

\section{CONCLUSION}

In the present study, 51 patients with gastrointestinal and pancreatic fistulas were enrolled and received somatostatin, octreotide or SMT. The spontaneous fistula closure rate was higher in the patients receiving somatostatin or octreotide than in the controls, at a similar cost. No statistically significant differences were established between the two drugs.
11. Spiliotis J, Briand D, Gouttebel MC, et al. Treatment of fistulas of the gastrointestinal tract with total parenteral nutrition and octreotide in patients with carcinoma. Surg Gynecol Obstet 1993;176:575-80.

12. Pederzoli P, Bassi C, Falconi M, et al. Conservative treatment of external pancreatic fistulas with parenteral nutrition alone or in combination with continuous intravenous infusion of somatostatin, glucagon or calcitonin. Surg Gynecol Obstet 1986;163:428-32.

13. Nubiola-Calonge P, Badia JM, Sancho J, et al. Blind evaluation of the effect of octreotide (SMS 202-995), a somatostatin analogue, on small-bowel fistula output. Lancet 1987;2:672-4.

14. Nubiola-Calonge P, Badia JM, Martinez-Rodenas F, et al. Treatment of 27 postoperative enterocutaneous fistulas with the long half-life somatostatin analogue SMS 201-995. Ann Surg 1989;210:56-8.

15. Martineau P, Shwed JA, Denis R. Is octreotide a new hope for enterocutaneous and external pancreatic fistulas closure? Am J Surg 1996;172:386-95.

16. Edmunds LH, Williams CM, Welch CE. External fistulas arising from the gastrointestinal tract. Ann Surg 1960;152:445-71.

17. Ridgeway MG, Stabile BE. Surgical management and treatment of pancreatic fistulas. Surg Clin N Am 1996;76:1159-73.

18. Jenkins SA, Berein A. Review article: The relative effectiveness of somatostatin and octreotide therapy in pancreatic disease. Aliment Pharmacol Ther 1995;9:349-61.

19. Dorta G. Role of octreotide and somatostatin in the treatment of intestinal fistulae. Digestion 1999;60(Suppl 2):53-6. 


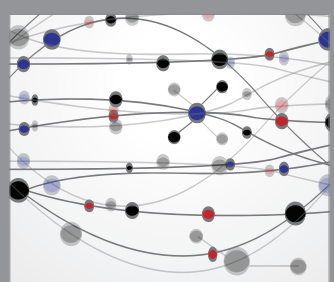

The Scientific World Journal
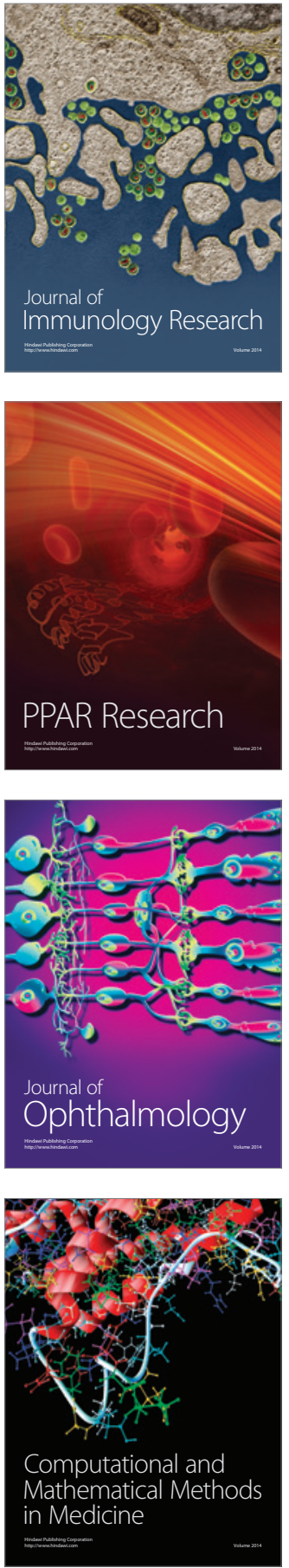

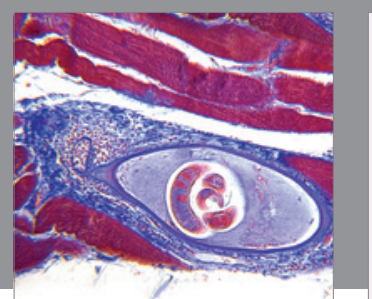

Gastroenterology Research and Practice

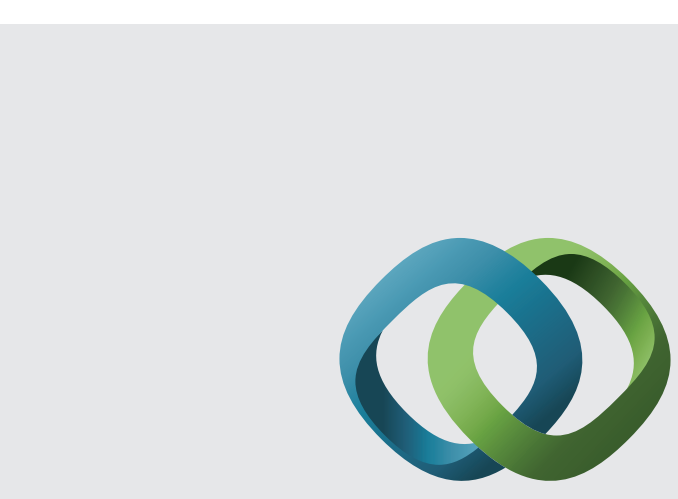

\section{Hindawi}

Submit your manuscripts at

http://www.hindawi.com
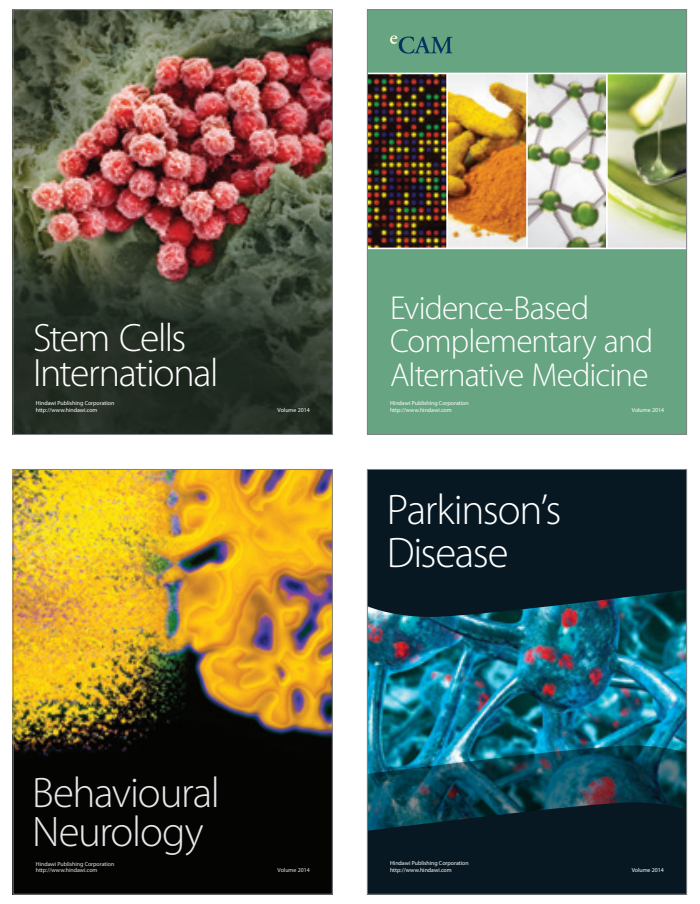
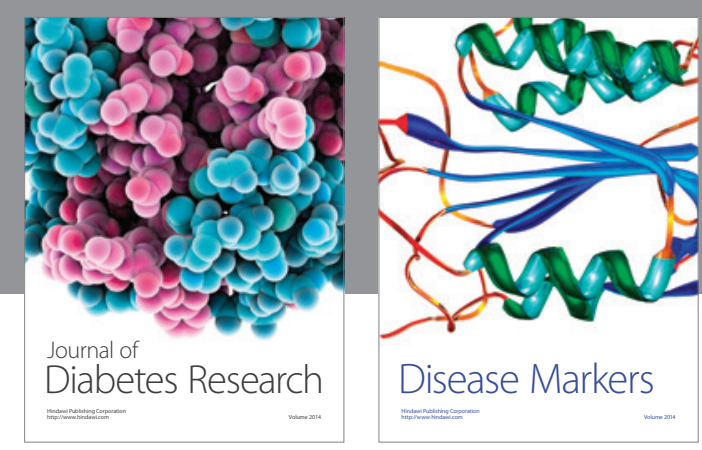

Disease Markers
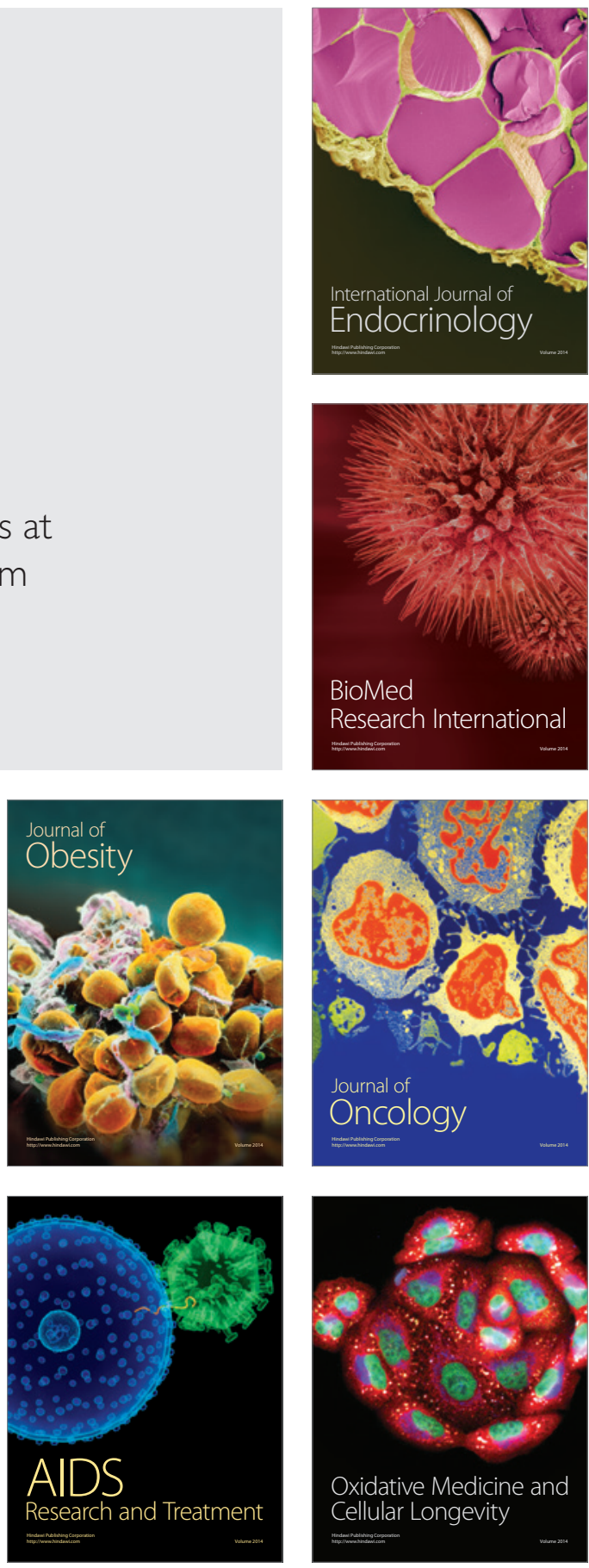